\title{
Relational place-making in Latvian countryside: Straupe and Kaldabruña case
}

\author{
Dina Bite ${ }^{1, *}$ and Zenija Kruzmetra $^{2}$ \\ ${ }^{1}$ Rīga Stradinsš University, Department of Humanities, Riga, Latvia \\ ${ }^{2}$ Latvia University of Life Sciences and Technologies, Institute of Social Sciences and Humanities, \\ Jelgava, Latvia
}

\begin{abstract}
The paper deals with the relational place-making term describing it through the two examples of Latvian countryside. Straupe and Kaldabrunga have developed strong social networks and cooperation during more than 10 years. Both cases are built on certain values that gather similar people and organisations around them. Administrative and social borders are not as important as the purpose of coming together and maintaining of social values. Relational place-making approach can also give an alternative view of consumers' society, as social agents involved tend to assign specific meaning to their actions and interactions. Relational place-making approach is powerful enough to bring up new ideas and implement new economic and social activities, and both theoretically and practically offer a new logic for trans-territorial relations and rural development.
\end{abstract}

Key words: relational place-making, Latvian countryside, rural development.

\section{Introduction}

The idea of the topic emerged after several published papers about the role of culture in the revitalisation of rural territories in Latvia. Data were collected during the National Research Programme ECOSOC (2014-2017) when authors noticed relatively high activity of rural communities in order to save and develop their places. Local activities that are directed towards urging local people to take responsibilities about themselves and their place have become a natural path of endogenous and neo-endogenous development in many rural counties of Latvia. The role of human capital and social resources is appreciated more and more in rural territories. The practice of involving different social agents in their activities and networks has led to the relational place-making approach.

Relational place-making as an approach to rural development gives a new insight into activities of rural communities and developed practices. The aim of the paper is to describe two cases that have been established and developed in rural territories of Latvia from the point of view of the relational place-making approach. The sequence of the paper is the following: theoretical description of the relational place-making perspective, methodology, the description of Straupe and Kaldabruna cases, discussion and conclusion.

\footnotetext{
* Corresponding author: Dina.Bite@rsu.lv
} 


\section{Theoretical insight}

Relational place-making is one of the terms that have been related to rural development through last years. Relational place-making (also place-shaping and place-framing) concerns such a way of interactions or relations between social agents that shapes development and is a key to social innovation [1,2]. Dutch rural sociologist Bettina B. Bock leads the discussion on rural development further and offers a term "nexogenous approach" that means "importance of reconnecting and binding together forces across space", including endogenous and exogenous resources, and necessity to apply this concept especially to marginal areas [1]. Relational approach seems to be a relatively new way of exploring and enabling rural development through emphasis on social networks much more than on static territories and relations between them [3]. Similar view describes relational places as a new "coming together" kind of places [4]. It stresses the importance of social connections. Relational approach can be analysed through a sociological point of view using agent network theory, system theory etc., as well as postmodern perspective where borders between places and structures merge, and quite flexible and unsavoury practices emerge in the foreground. As a sociologist of postmodernism Zygmunt Bauman wrote, "Culture no longer refers to a structure that imposes boundaries, but is seen as a critical process in which individuals transcend boundaries. The "cultural stance" is a questioning position in which the existence of multiple realities is recognized" [5]. Also, territorial development becomes "a variable set of interconnected places" and places are seen as "nodes in a dynamic network of interactions" [6] and successfully cross stereotypical borders of urban and rural territories. For example, Danish researcher Anne-Mette Hjalagar describes the "new trans-territorial logics" that emphasize rural enterprises as primary agents in partnership building [7]. Thus, flexible connections, networks and relations are prevailing over static perception of places.

From the geographical perspective, relational place-making is defined as a "networked, political processes of place-framing", analysing it as a conceptual part of the politics of place, networked politics and networked place [8]. This perspective highlights co-existence of different individual and collective views towards place-making, shared place understandings around these views and competition between them consequently. As the place is actively made and remade through cultural, discursive and material practices [9], these views and accordingly results of place-making are flexible and continuously changing. Further development of the geographical approach towards relational place-making exactly highlights temporary aspect [10]. According to theoretical phases of place-framing - "naming/blaming, claiming, and practicing - place-frames may go through multiple rounds of re-articulation as a result of the converging or diverging interests or understandings of places among actors" $[10,11]$. It affirms that even if social agents involved have agreed on particular aims or practices, they need to "re-affirm" these agreements from time to time. It can be considered as a systemic flow of negotiations and re-articulations of the meaning of the place.

Relational place-making approach as well as cultural assets is also proved as an alternative for filling the gaps in infrastructure in resource-limited communities. Theoretically, significant components of relational approach are traditional authority, strategic leadership of non-profit sector, funds, diaspora linkages, social and cultural assemblages, and inclusion of all stakeholders [12]. Necessity to have strong leadership is confirmed by several studies $[7,13]$ and real needs of rural communities. Leadership brings out a cluster of important functions and facilitates the territorial development and also is a ground of relational placemaking.

The importance of relational place-making is also recognised by the OECD and the European Commission, thus bringing new philosophy and style of operating [12]. There have been several attempts to implement it into policies. For example, Scotland has 
developed their place-based policy approaches considering following general principles of place-based development: mobilising endogenous potential, harnessing creative energy and knowledge, engaging an array of interests and social agents across diverse territories and multiple scales, supported by effective and adaptable institutions [14, 15]. In particular, they highlight the role of public sector institutions that has to involve and "re-think" how to engage communities [14]. Similarly, the UK and the Nordic countries have been developing institutional and financial support for rural social innovations including social economy, sharing of responsibilities between public, private and nongovernmental sector, and considering relational networks as a main source for implementing social changes [16].

Considering all above-mentioned theoretical material in relation to Latvia, there are some peculiarities in the area of moving towards the relational place-making approach. We cannot find specific plans and policies that support relational place-making in rural territories on national level. Local governments are starting to appreciate local human resources; however existing policies of place development are more adaptive to the rules given by central government, potential sources of financing and actually follow to a kind of inertia of previous policies. At the same time LEADER programme as an EU mechanism operates well and encourages rural communities to develop cooperation and social networks. Shrinking population and infrastructure as well as centralisation of public institutions during last decades have forced local people to look for alternative surviving ways and to almost automatically choose relational place-based strategy. This is a way how a significant part of villages and counties (communities) have surpassed formal statements and directions that come "from above". As authors have mentioned before [17], local agents like rural NGOs, entrepreneurs, sometimes local governments seem like pioneers and drivers of changes and territorial development implementing new products, new economic and social structures as well as new ways of thinking. However, there is the problem of fragmentation and instability of such structures, as they are not linked to any kind of support.

\section{Methodology}

During the implementation of the research project in the framework of the National Research Programme ECOSOC (2014-2017) best practices for building local communities and renewing rural territories were collected. The cases of Kaldabruna and Straupe stood out of the context because of strong network both of local and external social agents. They have proved the thesis of endogenous and also nexogenous territorial development and can offer more or less replicable social practices.

Case study strategy was chosen in order to analyse phenomena in their context [18]. Document analysis (local and national policy documents, reviews, and statistics data) and observation were used initially during two or three years (2016-2019). Semistructured individual and group interviews were conducted with the representatives of networks involved until the information collected was saturated enough $(n=12)$. The content of interviews has covered both ideological principles of establishing relational networks as well as practical issues and description of daily life and practical examples.

As relational place-making is not widely explored in Latvia, qualitative approach of social researches was chosen. Also, research questions are quite open: 1) what social agents are involved in the network of analysed cases? 2) What influences the dynamics of the network established? 3) What are the main consequences of the network in terms of relational placemaking? Interpretative analysis of qualitative research approach was used and the following discussion in the theoretical framework developed. 
The paper deals with the widening of understanding of relational place-making cases in Latvia that could help to design potential policies in order to support existing practices as well as increase knowledge about their features, development patterns and implications.

\section{Straupe case}

Straupe is a small parish (1341 inhabitants in July 2018) in the Pargauja district, which is located in the middle of Latvia, about $80 \mathrm{~km}$ northwest of Riga, with a rich cultural and historical heritage [19].

Straupe Farmers' Market is at the heart of Straupe's case, which was launched as a project idea in 2007 under the auspices of Straupe Tourism Society. In 2010, 5 activists founded the association "Healthy in City and Countryside", which continued to develop the idea of the fair. At the time of its creation, the Latvian legislation did not allow for the regular rural market, therefore, the association, in cooperation with the representatives of Slow Food movement in Riga, achieved favourable legislative changes. The market is open twice a month on Sundays. It aims to support local producers and "create the conditions for a shorter route to healthy rural products to the consumer". The motto of the store is: "Growing ourselves. Making ourselves. Selling ourselves" [20]. Straupe Rural Benefits Market is the only one in the Baltic that is a member of the Alliance of "Slow Food International Earth Markets" and is eligible to operate under this association's logo. This means that the products coming to the market are produced according to the Slow Food philosophy - they are local, seasonal and high quality, cultivated in good faith, respecting nature diversity and thinking about environmental sustainability [20].

As the organizers of the fair admit, the ideas have to be developed gradually, considering leaders or people who believe in the idea and are ready to represent it as the main driving force. Gradually, the association has developed contacts with local government, manufacturers, sales partners, buyers, other non-governmental organizations, the planning region, policy makers, entrepreneurs, cooperatives, international partners in the Slow Food Movement (Italy, Estonia, etc.).

In the history of its existence, the shop has created several successful companies, producers who have started their activities gradually: "He bakes wonderful bread. You persuade him. He says it's no big deal, I don't do anything special. Then he comes back and sees that some people like his products. Then he understands that his stuff is good. Then he makes the next 10 buns. And then he registers with the Revenue Service. And so, they go forth, the entrepreneurs".

As the chairman of the board of the association emphasizes, the organizers of the market consider this the most important function - the opportunity given to local producers to develop their own business, which has raised the self-assurance of the manufacturers and confidence in their product. Especially in rural areas, the creation of such relatively unconventional employment structures is very important: "They start looking at their work with different eyes because they see that there are same problems all over the world, and that people everywhere work and overcome them". On a larger scale, it is the home producers who can preserve a particular culture, retaining its original value and idea, as well as practical skills and skills of various crafts.

Their customers as another part of the network are described as a relatively prosperous part of the Latvian population seeking true values. There are quite many buyers with small children as well as buyers who support a certain lifestyle: "But there are also those who just go to enjoy the atmosphere". The market is mostly visited by the residents of the surrounding counties and cities, but there are many regular customers from Riga, as well as from remote locations and foreign countries. 
With regard to social networking, the organisation's policy can be seen as cautious, with no intention of expanding the network and gaining popularity, but faithfully representing the declared values and philosophy. For example, domestic producers and craftsmen who meet certain criteria are invited to trade and local producers are preferred. This is in line with the idea previously stated in the theoretical material that a certain part of the local community has a certain vision of what ideas should be implemented. It should be noted, however, that these ideas are not always related to the purpose of developing a particular place. Most often, the goals stem from private initiative, perhaps for rational reasons, such as in this case, from the desire to provide their family with good products and to create a place for local producers to sell their products. Only afterwards is the scale expanding to the understanding that it is possible to influence a wider audience with their activities, for example, realizing that tourists, when coming to the market, also see the culture of the place and nation, its everyday life and traditions. As a result, community leaders must exhibit a sense of responsibility not only for the realization of a narrow idea, but also for its wider impact.

Another social function worth mentioning is the renewing of awareness of the historical and cultural monuments. In 2016 the association started cooperation with the owners of Straupe Horse Post Station [21], which is currently the venue of the market. In a broader sense, this can be described as a successful collaboration that provides buyers/visitors with a specific framework vision or idea, and includes a wide range of activities (market, tours, rental of premises, etc.) to integrate the Horse Post Stations as an old Hanz trade road stop pointing out its historical and social significance: "This is a wonderful case when the landlord did not close up staying in his own little world but opened it to the public."

In general, it can be said that a stable community has been established around Straupe Market, which maintains and supports certain values that serve as basis for the network of agents. For individual projects that are limited in time and place, the range of cooperating partners is being expanded, but the core group for the operation of the market remains practically unchanged. One of the essential functions of the organizers of the market is advising entrepreneurs, non-governmental organizations, and cooperatives on how to develop similar types of activities. Leaders act as mentors for people from other regions of Latvia and also from abroad: "We are also giving a push to some extent in all regions of Latvia, because we have large number of visitors". At the same time, it is not possible to respond to all the calls for cooperation due to the capacity and values of the organization. Therefore, this network is considered as flexible and at the same time stable.

Referring to the theoretical material on relationship re-articulation, the following examples can also be identified in the case of Straupe, e.g., they have accepted a practice that not only organizers, but also the producers themselves share their experiences in seminars. Thus, the role of one social agent in this network can be flexible.

The case of Straupe Market confirms the theoretical concepts of the importance of social resources in the development of a place: "There may be all kinds of money at the bottom, any projects... if not for the person who carries the idea out and makes it true, there is zero value to all research and stimulus from the outside".

Summarizing the information about the Straupe Market, it can be concluded that in this case a certain value-based view of the development of the site is realized, which does not submit to the demands of the surrounding consumer society and thus offers an alternative view on the development of a certain area and also the place. Relational place-making, even if not called by this name, is being implemented and has a significant impact at both local and national level. Social relations are formed and strengthened over geographical constraints. 


\section{Kaldabruņa case}

Kaldabruņa is a small village in Jēkabpils county of Rubene parish, located in the eastern part of Latvia, $153 \mathrm{~km}$ from Riga. The population in the village is very small. According to the data of the Statistical Office of Latvia, 118 residents lived in the village in 2000, but in 2018 only 59 [22]. The village has a very poor infrastructure - no school, no store, no post office, no preschool etc. There are poor quality ground roads in the area, which makes the village in to a marginal area.

However, thanks to the activities of local leaders, since 2008 the place has slowly come to life and gained both the national and international recognition. The former school building is run by the Association "Watermarks". The activities of the Association are focused on the following directions: environmental protection and sustainable development, development of civil society, art and culture, education and development of children and youth [23].

The most visible activities of the Association are related to various artistic activities, such as the annual Hay Days, the exposition of the Meadow Museum, concerts, artists' plenary sessions, the glass workshop, and the provision of various social services to the local population. There is the internet available in the Association's facility, laundry can be washed, practical help is provided to people in crisis, etc.

As the population is small and the infrastructure is scarce, the Association's only option is to network with other social agents. The head of the Association also works in the local LEADER partnership. An attempt has been made to bring the experience of Kaldabruņa into the neighbouring areas. In cooperation with neighbouring parishes and counties, a popular theme route has been established in 17 small settlements "Sēlija Islands" [24] and a $28 \mathrm{~km}$ bicycle route "The First Journey of Jānis Rainis" opened. In this way, local associations, in cooperation with municipalities and other agents work for the sake of economic and social revitalization of rural areas. Social networks and cross-border relationships have been designed purposefully and resolutely to create more opportunities to attract funding and thus develop the territory. The agents involved in the Selija Islands project have created their own operational philosophy called "island emanation": "How big is the emanation from the place you maintain. This place is sometimes geographic, sometimes it is purely spiritual, and its geographic significance is not so great". Representatives of the Association especially emphasize the spiritual and emotional aspects to the development of the place. Otherwise, the services and products offered will quickly exhaust themselves and become one of the standard products. In other words, the social agents involved in the relationship network must constantly create and maintain certain values or the story of the place. At the same time, the "emanation approach" expresses a vision of site development, cultivates certain values, and takes care of site marketing, social and economic development. Moreover, "Sēlija Islands" is formed as a place of inspiration, good practice that can be taken over by other rural districts: "For example, the association right here in Dviete... the girls said - if you can do it, we can as well! Now they are very strong, now they only need us as friends".

More than 10 years of activity from Kaldabruņa have served as inspiration to several neighbouring counties and also more distant guests. Mutual cooperation allows for reciprocal complementarities, specialization and synergy. Consequently, there are other nongovernmental organizations in the region and also nationally, local government and its institutions (e.g., schools), local community, artists from different places in Latvia and also in Lithuania, representatives of universities or academic environment etc. among the network partners of Kaldabruņa Association. Kaldabrunga is an example of how borders between populated areas, cities and fields are dissolved and the focus can be on ideas and people with certain values. For example, in the Church of Chervonca, which the Association is gradually trying to renew, concerts with the participation of well-known artists, classical 
music, etc. take place. Interestingly, the idea of restoring the Church of Chervonca was proposed by artists who came to visit. This means that within a relational network, local people have the opportunity to look at their resources from the outside and see other opportunities.

The case of Kaldabrunga is one of the rare networks in Latvia that has deliberately and purposefully set culture as the most important development resource. It is not an accidental or copied action, but a purposeful and meaningful initiative. As a result, communities in the area are actively looking for and developing a variety of local tangible and intangible cultural resources. As the Association explains, the development of a place in a cultural context can be explained by the use of traditional cultural resources and the creation of a new added value.

The existence and dynamics of the network in the case of Kaldabruna is strongly influenced by national policies, such as how much financial resources are allocated to the nongovernmental sector. As the Association reveals, in recent years the support for rural areas has been channelled more towards local governments than to civil society, which undoubtedly affects the ability of the non-governmental sector to realize its vision of local development. Likewise, the local population underlines the constant ignorance and worry about the status of small schools in the region, as the state's policy is to reduce the number of schools without thinking about the consequences of such decisions. Hence, the relationships and trust unique to small rural communities are eroding and people tend to deal with it individually, most often by moving away from so-called non-viable rural areas.

The case of Kaldabruna reveals the dynamics of networking also in relations with the local community. In principle, the Association has in 10 years created a legal and practical framework for local people's activities. At present, however, Association's representatives disclose that the local community has a more consumer-oriented approach, namely the desire to enjoy existing opportunities, such as attending cultural events, rather than engaging themselves or starting their own business. Commenting on the theories of these situations, one of the visions of site development has become dominant in this small village, while other alternative visions are in a latent position. Undoubtedly, this is also caused by the small population and infrastructure constraints.

Evaluating social and economic consistency in the example of relational place-making in Kaldabruņa, tourism activities and their contribution are at the forefront. Tourists from Latvia and foreign countries are visiting Kaldabruņa, and "Sēlija Islands" is becoming a more and more popular tourist destination, which shows that the strategy of cooperation and networking is the right one. Local communities and the non-governmental sector in the neighbouring areas and elsewhere in Latvia have also become more active. Several local activists have raised their human capital through education, for instance, in the field of tourism. Several jobs have been created, cultural and tourism activities bring economic benefits to local entrepreneurs, etc..

\section{Discussion and conclusion}

In both cases, the informants admit that they have not thought about their activities in any theoretical categories, so the interviews also serve as an educational, self-reflective and cooperative factor. This aspect also confirms that rural communities have developed relational place-making as a natural response to local, national and global challenges, having arrived to the need and development of a relational network through learning and experience.

There is a certain vision and realization of ideas about the development of the place in Kaldabruņa and Straupe. For various reasons, they are dominant in given areas and do not especially compete with alternative views. Operational and development visions are based on certain values and their maintenance practices. In both cases, there is a periodic re-articulation 
of interests, directions of action, and social norms, but this takes place within the framework of existing moral norms and values.

Creating and realizing a vision of place development always encounter the characteristics and manifestations of the consumer society. The direction that is maintained in both Kaldabruņa and Straupe includes a deeper understanding of site development based on cultural resources. Both cases are considered good practices precisely because over time their creators and implementers have not used any quick marketing tricks that would have quickly drained their social practices. On the contrary, community leaders have fought hard for each product or each cooperation practice to represent certain values.

An important conclusion of the study is the dissolution of social borders between places, cities and rural areas, social groups and even social classes. The assertion that administrative or social borders are irrelevant in the cases investigated would be confusing, but the existence of borders was not identified as a problem. Latvia's countryside is birthing a new logic of place development and a new form of community, which has certain values and a view on the order of things at the heart. In other words, boundaries are formed around a set of values, and the specialization of cultural and economic activities is gradually taking place. Relational place-making is a tool for implementing these activities.

The study confirms the importance of social resources for place development. Attraction of new human resources, as well as the unlocking of the potential of human resources, is important in both studied places, however, in the case of Kaldabrunna, the importance of infrastructure becomes more visible. The situation in Kaldabruna illuminates a significant problem with relational place-making. If there is not enough infrastructure and institutional support, if the human capital, social and cultural capital of the local population falls over time, the structures created by relational place-making are not as sustainable and lasting in themselves. They need new human, material and financial resources, as well as a supportive regulatory framework. In the case of Latvia, it could be argued that the official rural policy is lagging behind the established structures in the countryside. To some extent, rural people have shown a direction for further development, but the support of central power is currently insufficient.

The results of the research, to some extent, challenge the traditional notions of the countryside as a place requiring marginal and special policies. As informants say, a large part of the rural population is well-off, have opportunities to develop different ideas, and cultural and entertainment opportunities are often more accessible than in the city. For example, people deliberately choose to visit a fair or cultural activity in the countryside or in small towns, where the relative "quality level" is not lower than in the city, but where there are other benefits. Thanks to the processes of globalization and the activity of the local population, the range of goods and services in the countryside is not very different from the cities. The dependence of the rural population on cities is therefore diminishing, and the ideas offered by the countryside can compete seriously with cities. However, as stated above, the dominant (political) discourse in Latvia does not appreciate or underestimate rural resources.

Summarizing the above, there are relational place-making features in rural areas of Latvia, where both endogenous and exogenous forces are engaged in a single network, overcoming administrative and social boundaries. The research carried out generally confirms the theoretical assumptions of the importance and functions of relational place-making. This approach helps to better understanding the processes, actions and interactions in rural areas. Future studies call for analyzing sustainability issues and dynamics of existing relational networks. 
Authors acknowledge the National research programme 2014-2017 ECOSOC and The National research programme "Latvian heritage and future challenges for sustainable development" 2018-2021, research project "Towards sustainable development and inclusive society in Latvia: response to demographic and migration challenges".

\section{References}

[1] B.B. Bock, SociolRuralis 56, 552 (2016)

[2] M. Woods, Cultural Sustainability and Regional Development (2015)

[3] M. Woods, J. Heley, ROBUST D1.1 (2017)

[4] J. Anderson, Environ. Planning 30, 570 (2012)

[5] V. Marotta, Thesis Eleven 70, 36 (2002)

[6] B.B. Bock, TARRN Meeting (2018)

[7] A.M. Hjalager, Local Econ. 32, 34 (2017)

[8] J. Pierce, D.G. Martin, J.T. Murphy, Trans. Inst. Br. Geogr. 36, 54 (2011)

[9] A.L. Bain, F. Landau, Urban. Aff. Rev., 1 (2017)

[10] A.Y. Zhang, Geoforum 90, 91 (2018)

[11] S.L. Van Neste, D.G. Martin, Trans. Inst. Brit. Geogr. 43, 47 (2017)

[12] C.F. Che, Societies 8, 12 (2018)

[13] O. Potluka, J. Kalman, I. Musiałkowska, P. Idczak, Local Econ. 32, 297 (2017)

[14] J. Atterton, RESAS Strategic Research Programme Research Deliverable 3.4.2 (2017)

[15] L. Pugalis, G. Bentley, Local Econ. 29, 273 (2014)

[16] A. Copus, L. Perjo, L. Jungsberg, L. Randall, H. Sigurjónsdóttir, Nordregio Working Paper, 2 (2017)

[17] D. Bite, Ž. Krūzmētra, Int. J. Econ. Manag. Syst. 2, 277 (2017)

[18] C. Robson, K. McCartan, Real World Research, $4^{\text {th }}$ ed., John Wiley \& Sons Ltd. (2016)

[19] Straupe, world's smallest Hansa town. Available: http://hansa. pargaujasnovads.1v/en/

[20] Slow Food Straupe. Available: https://straupestirdzins.1v/en/us/

[21] Straupe Horse Post Station. Available at: https://zirgupasts.lv/

[22] CSP data bases. Available at: https://data1.csb.gov.1v/pxweb/lv/iedz/ iedz__riga/RIG010.px/table/tableViewLayout1/?rxid=32f317cb-2d8a46f $1-a b 11-b 1 f a 54391 a b 4$

[23] Association "Ūdenszīmes" ("Watermarks"). Available at: http://www . udenszimes. Iv/cms/par-mums/

[24] Sēlijas Rural Partnership cooperation project "Sēlijas Islands". Available at: http://www. laukutikls.lv/nozares/lauku-telpa/notikumi/2017-11-01000000-lidz-2017-11-17-000000/selijas-lauku-partneribu 